\title{
Infrared spectroscopy technique for differentiation of genuine and counterfeit engine oil - a forensic aspect
}

\begin{abstract}
The counterfeit and genuine engine oils differ in chemical and physical composition. Aim of this study is to investigate the crime of cheating by analyzing engine oil samples with the help of FTIR. Identifying the engine oil additives like ZDDP (Zinc dialkyl dithiophosphate) at $978 \mathrm{~cm}^{-1}, 654 \mathrm{~cm}^{-1}$ and poly isobutylene succinamide at $1704 \mathrm{~cm}-1$ by Infrared spectroscopy in support with parameters like Specific Gravity, Kinematic Viscosity, Flash Point and Total Base Number. The result implies that the counterfeit engine oil is crudely recycled oil as it shows depleted peaks of additives at their characteristic wave numbers in Infrared spectra.
\end{abstract}

Volume 3 Issue 3 - 2017

\author{
Joshi DC, Chutke NL \\ Directorate of forensic science laboratories, India \\ Correspondence: Joshi DC, Deputy Director Directorate of \\ Forensic Science Laboratories, State of Maharashtra, Mumbai-98, \\ India, Email nitichutke@gmail.com
}

Received: July 07, 2017 | Published: September 15, 2017

Keywords: FTIR, counterfeit, engine oil, forensic, surfaces

Abbreviations: API, American petroleum institute; SAE, society of automotive engineers; JASO, Japanese automotive standard organization; ZDDP, zinc dialkyl dithiophosphate; ASTM, American standards for testing and materials; FTIR, fourier transform infrared spectrometer

\section{Introduction}

Lubricating motor oils are used to reduce friction and wear by interposing the film between the moving surfaces. Tallow was used to lubricate chariot wheels before 1400BC. Although, fundamental principles of friction and lubrication were developed later in nineteenth century; the use of additives in lubricants has progressed rapidly since ca 1930; synthetic lubricants were developed largely since World War II. ${ }^{1}$ In twentieth century lubrication technology has advanced far beyond and base mineral oil are now blended with additive packages for their different utility as Engine oils which again classify into Diesel and Petrol Engine oils, Gear oils, Hydraulic oils and so on. ${ }^{2,3}$ The high cost of developing these advanced lubricants to meet the standards used worldwide such as The society of Automotive Engineers (SAE) standard oil classification system, American Petroleum Institute (API) and Japanese Automotive Standard Organization (JASO) increased the cost of the lubricant oils used for specific purpose, this in turn have motivated criminal activities to indulge in making counterfeit motor oils, their packaging and selling in open market.

The counterfeit oils have posed great loss to companies involved in oil manufacturing. These oils also pose threat to the machine in which it is used and to the environment which is further polluted by the engines which used these low grade oils. Counterfeit oils are mainly used oils which are filtered cleaned, centrifuged, bleached, dyed and in some cases detergents and hydroxides are added to match base numbers. ${ }^{4}$ Engine oil is tested for parameters like Specific Gravity, Viscosity, Flash Point and Total Base Number. Infrared spectroscopy (FTIR) which is an important tool extensively used for condition monitoring of used motor oils, it can also be the useful tool for identifying the additives like ZDDP (Zinc dialkyl dithiophosphate) an anti-wear-antioxidant and poly isobutylene succinamide a dispersant additive. These additives deplete on usage and is either not found or found in low levels in used or recycled oils. ${ }^{5,6}$ Thus differentiation of genuine and counterfeit oil is possible using infrared spectroscopy along with other test parameters. In the present study counterfeit and genuine Castrol Super plus CF4 15W40 engine oil was analyzed for parameters such as Kinematic Viscosity, Specific gravity, Flash point, Total Base Number and major technique Infrared spectroscopy for analyzing oil additives.

\section{Materials}

Fourier Transform Infrared Spectrometer (FTIR) spectra were taken using Bruker Tensor 27 FTIR instrument with a resolution of $4 \mathrm{~m}^{-1}$ at 64 scans. Kinematic viscosity was performed on Automatic Kinematic Viscometer Tanaka AKV-201, Flash point was done on Tanaka Flash point apparatus FC-7 fitted with Pensky Martrin Closed Cup Unit APM-7. Enertech Potentiometer used for potentiometric titration to determine Total Base Number,(TBN). Chemicals used for TBN analysis, Toluene, Isopropyl Alcohol, and Hydrochloric Acid all were of Analytical grade procured from of eMerck (I) Ltd.

\section{Experimental}

The chemical and physical parameters analyzed for Counterfeit Castrol CF4 15W40 oil and Genuine Castrol CF4 15W40 engine oil are based on standard analytical methods to provide and interpret data of counterfeit and genuine engine oil. Specific Gravity, Kinematic Viscosity, Flash Point, and TBN analysis were performed according to American Standards for Testing and Materials (ASTM) chemical methods. ${ }^{7}$ FTIR spectra were recorded from $4000 \mathrm{~cm}^{-1}$ to $400 \mathrm{~cm}^{-1}$. A small quantity about $0.2 \mathrm{ml}$ of oil was taken in KBR cell. The FTIR spectrum polyisobutylene succinamide was recorded at $1704 \mathrm{~cm}^{-1}$ and Zinc dialkyl dithiophosphate was recorded at $978 \mathrm{~cm}^{-1}$ and $654 \mathrm{~cm}^{-1}$, for counterfeit and genuine engine oil. ${ }^{8}$ The spectral data along with the chemical and physical properties of genuine Castrol CF4 15W40 engine oil and counterfeit Castrol engine oil was then interpreted to differentiate between the duos. 


\section{Results and discussion}

Physical and chemical parameters of engine oil provide all the important information regarding the health of the engine oil. Both genuine and counterfeit samples were tested for the parameters like Specific Gravity, Kinematics Viscosity, TBN, Flash point and molecular spectroscopy of additives like poly isobutylene succinamide and Zinc dialkyl dithiophosphate. Table 1 summarizes the physical and chemical parameters of Genuine Castrol CF4 15W40 engine oil (Sample 1) and Counterfeit Castrol CF4 15W40 oil (Sample 2). On the basis of results for specific gravity and flash point, it reveals that there is no much difference in the values of two samples and needs the supporting parameters like Viscosity and TBN. ${ }^{9}$

Table I Physical and chemical parameters of engine oil samples

\begin{tabular}{lllll}
\hline Samples & $\begin{array}{l}\text { Specific gravity at } \mathbf{2 5}^{\circ} \mathrm{C} \\
(\text { ASTM D I 298-99) }\end{array}$ & $\begin{array}{l}\text { Flash point }\left({ }^{\circ} \mathrm{C}\right) \\
\text { (ASTM D56-05) }\end{array}$ & $\begin{array}{l}\text { Total base number } \\
(\text { ASTM D2896) }\end{array}$ & $\begin{array}{l}\text { Kinematic viscosity at } 100^{\circ} \mathrm{C} \\
\text { (cst) }\end{array}$ \\
\hline (ASTM D445)
\end{tabular}

Viscosity of the fluid changes with the temperature, hence engine oils are formulated by Viscosity index improvers to withstand proper lubrication at higher temperatures. After oil is used viscosity of the oil either decreased due to any fuel dilution during the run or increases due to sludge formation by oxidation of the oil. The recycled oils do contain some amount of viscosity index improvers of the past formulation. The (Table 1) shows Kinematics viscosity of counterfeit oil sample is less than that of genuine engine oil sample at $100^{\circ} \mathrm{C}$. Kinematic viscosity at $100^{\circ} \mathrm{C}$ and specific gravity of the genuine engine oil are compared with the results of counterfeit engine oil (Table 1). The interpretation reveals that the values do not match the genuine engine oil; hence the other parameter TBN was performed. The TBN determines the amount of base to neutralize the sulfur byproducts namely sulfurous and sulfuric acids, to retard the corrosive damage to engine. The (Table 1) shows TBN value of genuine and counterfeit engine differs primarily; this implies that the counterfeit Castrol 15W40 may be crudely recycled used engine oil. To confirm this belief, both the samples were tested for Infrared Spectroscopy (FTIR). FTIR spectra from the range $4000 \mathrm{~cm}^{-1}$ to $400 \mathrm{~cm}^{-1}$ were recorded. The spectra of Genuine Castrol CF4 15W40 is shown in (Figure 1) and that of counterfeit Castrol 15W40 is shown in (Figure 2). Infrared spectra for two major additives, polyisobutylene succinamide and Zinc dialkyl dithiophosphate shown in (Figure 3) were studied. The FTIR spectrum in (Figure 2,3) shows characteristic absorbance at $1704 \mathrm{~cm}^{-1}$ for succinamide dispersant in Genuine Castrol CF4 15W40 engine oil and depleted peak in counterfeit Castrol CF4 15W40 sample at same wave number. Similarly Zinc dialkyl dithiophosphate antiwear additive shows infrared stretching vibration due to $\mathrm{P}-\mathrm{O}-\mathrm{C}$ bond between $950 \mathrm{~cm}^{-1}$ and $1020 \mathrm{~cm}^{-1}$ and $\mathrm{P}=\mathrm{S}$ bond between $640 \mathrm{~cm}$ ${ }^{1}$ and $665 \mathrm{~cm}^{-1}$ in Genuine engine oil sample and depleted peak in counterfeit oil sample in the respective wave numbers.

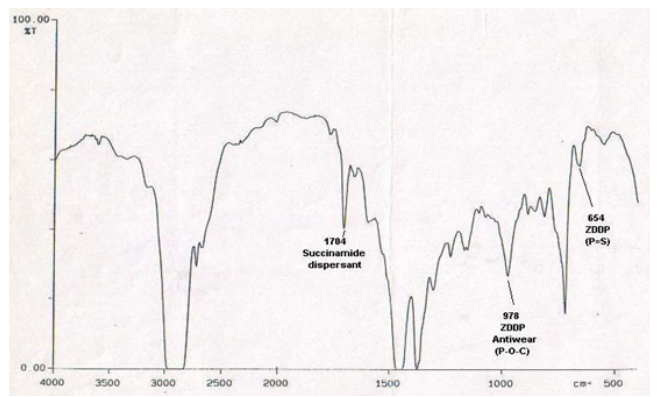

Figure I FTIR spectra of sample I (genuine castrol CF4 I5W40 engine oil).

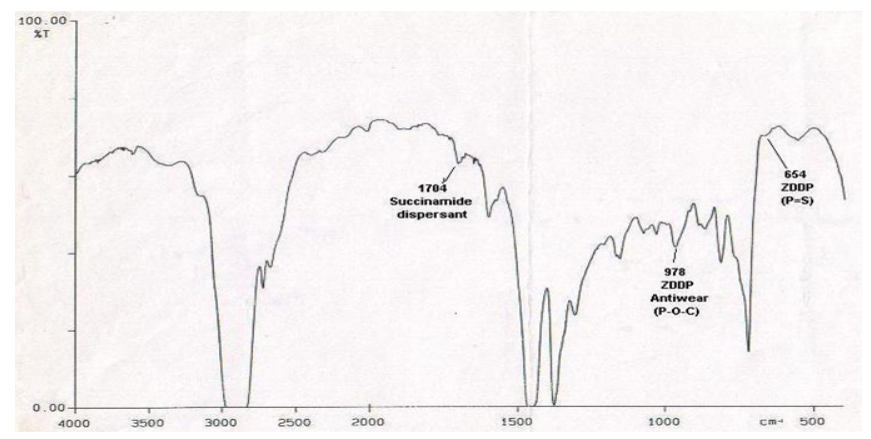

Figure 2 FTIR spectra of sample 2 (counterfeit castrol CF4 I5W40 engine oil).

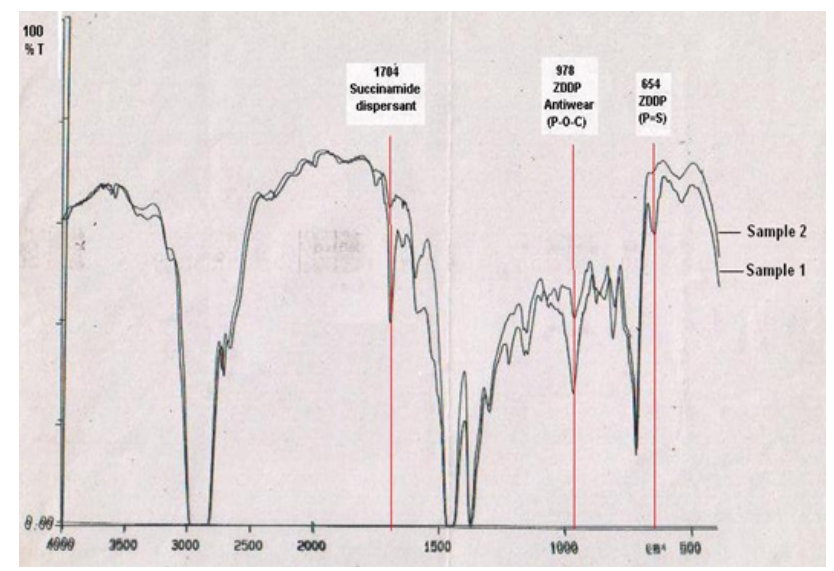

Figure 3 Overlays of FTIR spectra of sample I and sample 2.

\section{Conclusion}

The FTIR study reveals that there is a clear differentiation between genuine and counterfeit engine oil as shown in overlay of the two spectrums in (Figure 4). Also FTIR data implies that the counterfeit oil is crudely recycled oil as it shows depleted peaks of additives at their characteristic wave numbers. Thus the Molecular Spectroscopy in Forensic Analysis is proved to be a master tool in support of the other physical and chemical parameters like Specific gravity, Kinematic viscosity, Flash point and Total base Number, to differentiate the genuine and counterfeit engine oil samples so as to prove crime under cheating case (u/s 420 of IPC Act.). 
<smiles>CNC(=O)CN1C(=O)CC(NC(C)=O)C1=O</smiles>

succinimide headgroup

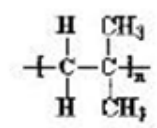

monomer of poly(isobutylene) tail

Polyisob utylene succinamide

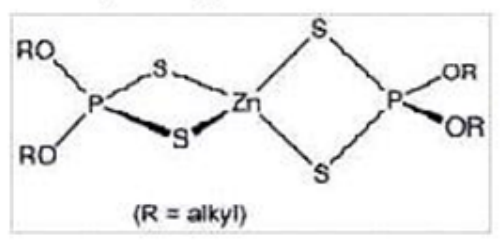

Zinc dialkyl dithiop hosp hate

Figure 4 Anti-wear and dispersant additives used in engine oil.

\section{Acknowledgments}

The authors wish to acknowledge, Director, Directorate of Forensic Science Laboratories, Mumbai, Govt. of Maharashtra, for his encouragement and keen interest in this research works.

\section{Conflicts of interest}

The author declares that there are no conflicts of interest.

\section{Funding}

None.

\section{References}

1. Krik Othmer. Encyclopedia of Chemical Technology -Lubrication and Lubricants. USA: Publ-Wiley Interscience Publication. 1981;1(26):1804.

2. Janina Zi. Differentiation of Motor Oils by Infrared spectroscopy and elemental analysis for crimalistic purposes. J Molecular Structure. 1999; (482-483): 533-538.

3. Dave Wooton. Molecular Spectrosopy-A Precision Lubrication Tool?, Practicing Oil Analysis Publ - Noria Corporation. 2003;5:1-7.

4. John R Dyer. Applications of Absorption Spectroscopy of Organic Compounds. Delhi, India: Publ-Prentice Hall of India (P) Ltd. 1965:2257.

5. Jayshree Bijwe, Amik Garg, OP Gandhi. Reassessment of Engine Oil Periodicity in commercial Vehicles. Journal of the Society of Tribologists and Lubrication Engineers. 1999;23-29.

6. Hosonuma K, Yoshida K, Matsunaga A. The decomposition products of Zinc Dialkyl Dithiophosphate in an Engine: Their interaction with Diesel Soot. Wear. 1985;103(4):297-309.

7. Mohammad A, Al-Ghouti, Lina Al-Atoum. Virgin and recycled oil differentiation: A Spectroscopic Study. $J$ Environ Manage. 2009;90(1):187-195.

8. ASTM; Annual Book of ASTM Standards, Sec.5 "Petroleum products, Lubricants and Fossil Fuels. Philadelphia: American Society for Testing and Materials Race Street. 1916;19103-1187.

9. Lubricating Oil Base Stocks Category. US-EPA, The Petroleum HPV Testing Group, Consortium Registration 1100997: 2003. 